\title{
CYCLOSTREPTIN BINDS COVALENTLY TO MICROTUBULE PORES AND LUMENAL TAXOID BINDING SITES.
}

Rubén M. Buey ${ }^{1 *}$, Enrique Calvo ${ }^{2 *}$, Isabel Barasoain ${ }^{1}$, Oriol Pineda ${ }^{3}$, Michael C. Edler $^{4}$, Ruth Matesanz ${ }^{1}$, Gemma Cerezo ${ }^{5}$, Christopher D. Vanderwal ${ }^{6}$, Billy W. Day ${ }^{7}$, Erik J. Sorensen ${ }^{8}$, Juan Antonio López ${ }^{2}$, José Manuel Andreu ${ }^{1}$, Ernest Hamel ${ }^{4}$, and J. Fernando Díaz ${ }^{1}$

From the ${ }^{1}$ Centro de Investigaciones Biológicas, Consejo Superior de Investigaciones Científicas, Ramiro de Maeztu, 9, 28040 Madrid, Spain, the ${ }^{2}$ Unidad de Proteómica, Centro Nacional de Investigaciones Cardiovasculares, Melchor Fernández Almagro 3, 28029 Madrid, Spain, the ${ }^{3}$ Departament de Química Orgànica, Facultat de Química, Universitat de Barcelona, Av. Diagonal 647, 08028 Barcelona, Spain, the ${ }^{4}$ Toxicology and Pharmacology Branch, Developmental Therapeutics Program, Division of Cancer Treatment and Diagnosis, National Cancer Institute at Frederick, National Institutes of Health, Frederick, MD 21702, ${ }^{5}$ PharmaMar, S. A. Avda. de los Reyes, 1, 28770 Colmenar Viejo, Spain, the ${ }^{6}$ Department of Chemistry, University of California, Irvine, CA 92697, the ${ }^{7}$ Departments of Pharmaceutical Sciences and Chemistry, University of Pittsburgh, Pittsburgh, PA 15261, and the ${ }^{8}$ Department of Chemistry, Princeton University, Princeton, NJ 08544. "These authors have contributed equally to this work. 


\begin{abstract}
Cyclostreptin, a natural product from Streptomyces sp.9885, irreversibly stabilizes cellular microtubules, causes cell cycle arrest, evades P-glycoproteinmediated drug resistance of a tumor cell line, potently inhibits paclitaxel binding to microtubules, yet only weakly induces tubulin assembly. In trying to understand this paradox, we observed irreversible binding of synthetic cyclostreptin to tubulin. This results from formation of covalent crosslinks to $\beta$-tubulin in cellular microtubules and microtubules formed from purified tubulin in 1:1 total stoichiometry distributed between Thr220 (at the outer surface of a pore in the microtubule wall) and Asn228 (at the lumenal paclitaxel site). Unpolymerized tubulin was only labeled at Thr220. Thus, the pore region of $\beta$-tubulin is an undescribed binding site that elucidates the mechanism by which taxoid site compounds reach the kinetically unfavorable lumenal site and explains how taxoid site drugs induce microtubule formation from dimeric and oligomeric tubulin.
\end{abstract}


The mitotic spindle is an important target in cancer chemotherapy ${ }^{1}$. Spindle function is dependent on microtubule dynamics, which involves stochastic gain and loss of $\alpha \beta$-tubulin heterodimers from microtubule ends. Growth or shortening depends on the activation state of tubulin, controlled by the exchangeable nucleotide bound to the $\beta$-subunit. "Activated" tubulin-GTP adds to microtubule ends, while "deactivated" tubulin-GDP dissociates from polymer ends and will not normally polymerize into microtubules.

Compounds that bind to tubulin arrest cells in mitosis and cause apoptosis. At intracellular concentrations far below the tubulin concentration, these agents interfere with microtubule dynamics ${ }^{2}$. Inhibitors of assembly, such as colchicine, inactivate tubulin, preventing microtubule formation. In contrast, microtubule stabilizing agents (MSAs), such as paclitaxel, bind preferentially to assembled tubulin, minimizing dissociation of tubulin-GDP from microtubule ends ${ }^{3}$. MSAs also induce assembly of the otherwise inactive tubulin-GDP ${ }^{4}$. In recent years, many structurally diverse taxoid site MSAs were discovered, including epothilone B and discodermolide, biochemically more potent than paclitaxel ${ }^{5}$, and cyclostreptin (FR182877) (Fig. 1a), which, while apparently less active than paclitaxel, has unusual biochemical properties $^{6}$.

Paclitaxel-stabilized, zinc-induced sheets of antiparallel tubulin protofilaments were used for construction of a model of tubulin with bound paclitaxel ${ }^{7}$, and, after fitting this model into electron density microtubule maps, it was concluded that paclitaxel binds to $\beta$-tubulin facing the microtubule lumen ${ }^{8}$. This model is supported by tubulin mutation data from cells resistant to paclitaxel and epothilones ${ }^{9}$.

Two points remain obscure in the biochemical mechanism by which taxoid site ligands induce tubulin assembly. First, examination of the binding kinetics of 
paclitaxel ${ }^{10}$ yields a high $\mathrm{k}_{\mathrm{f}}\left(3.6 \times 10^{6} \mathrm{M}^{-1} \mathrm{~s}^{-1}\right)$ inconsistent with a relatively inaccessible lumenal binding site. An exposed site is also supported by reduction in the paclitaxel binding rate caused by microtubule-associated proteins $(\mathrm{MAPs})^{10}$ and by antifluorescein antibody binding to a fluorescein labeled taxoid bound to microtubules ${ }^{11}$. These findings led us to propose an initial binding site for paclitaxel on the outer microtubule wall near pore type I, which is close to the lumenal site, followed by translocation of the drug to its lumenal site ${ }^{10}$. Since there is $1: 1$ stoichiometry for paclitaxel binding to $\alpha \beta$-tubulin, the two sites must be mutually exclusive, perhaps with a shared element.

Second while apparently the paclitaxel site exists only in assembled microtubules ${ }^{12}$, taxoid site drugs can induce microtubule assembly under conditions in which tubulin is normally unable to assemble and thus no binding sites can be demonstrated. Therefore, since assembly occurs, we postulated a low affinity binding site in tubulin dimers or oligomers, whose existence could not be demonstrated due to low paclitaxel solubility ${ }^{12}$.

Although cyclostreptin ${ }^{13}$ weakly stimulates tubulin assembly, it avidly binds to microtubules, strongly inhibiting the binding of other MSAs to polymer. In addition, cyclostreptin-stabilized microtubules disassemble at $0{ }^{\circ} \mathrm{C}$ more slowly than paclitaxelstabilized microtubules ${ }^{6}$. We have now found that cyclostreptin interacts covalently both in vitro and in cells with polymerized tubulin, blocking the binding of even the most potent taxoid site ligands. Moreover, cyclostreptin is fully active in multidrug resistant (MDR) A2780/AD cells overexpressing P-glycoprotein (P-gp), indicating that covalent binding might be a way to overcome MDR. With HPLC-MS, we found that two amino acid residues, Thr220 and Asn228 ${ }^{a}$, were modified in polymerized $\beta$ tubulin (Asn228 is near the taxoid site facing the microtubule lumen, Thr220 abuts 
pore type I), but only Thr220 was modified when cyclostreptin interacts with unpolymerized tubulin.

\section{RESULTS}

Cyclostreptin binds irreversibly to microtubules and blocks binding of taxoid site ligands. Since cyclostreptin strongly inhibits binding of taxoid site ligands to microtubules, we tried to detect microtubule-bound cyclostreptin. Cyclostreptintreated microtubules were analyzed by HPLC-MS. Controls showed that cyclostreptin should have been detectable, but the pellet extracts were devoid of the compound (Fig. 1b, black lines). Ligand in the supernatant (red lines) was greatly reduced following incubation of cyclostreptin with microtubules. In the absence of degradation products, cyclostreptin must have reacted irreversibly with the protein.

We examined competition among taxoid site ligands of different affinities for microtubules (discodermolide, epothilone B, epothilone A, cyclostreptin, and paclitaxel; $\mathrm{K}_{\mathrm{d}}$ 's at $35^{\circ} \mathrm{C}$ of $0.18,1.3,28,49$ and $70 \mathrm{nM}$, respectively $)^{5,6,14}$. The competition experiments were performed by adding labeled competitor before or after unlabeled ligand (Table I). All ligands except cyclostreptin behaved as expected if binding reversibly to the same site (order of ligand addition had no effect). With cyclostreptin, the feeble inhibition of discodermolide and epothilone B binding and strong inhibition of paclitaxel binding without a preincubation became near total inhibition with a preincubation. We also examined the binding to microtubules of 7-O[N-(2,7-difluoro-4'-fluoresceincarbonyl)-L-alanyl]paclitaxel (Flutax-2) a fluorescent analog of paclitaxel ${ }^{15}$, which bound with an apparent $K_{d}$ of $14 \mathrm{nM}$, but not to microtubules preincubated with cyclostreptin (Fig. 1c). 
Cyclostreptin and docetaxel displace Flutax-2 by different mechanisms. Cyclostreptin can displace Flutax-2 from stabilized microtubules with an apparent $\mathrm{K}_{\mathrm{a}}$ similar to those of paclitaxel and docetaxel ${ }^{6}$. To determine whether the same mechanism was involved ${ }^{15}$, we compared the effects of docetaxel and cyclostreptin on the kinetics of Flutax-2 dissociation (Fig. 1d).

Docetaxel displaces Flutax-2 from microtubules because $\mathrm{k}_{\mathrm{f}} \bullet[$ docetaxel] $>>$ Flutax-2 dissociation rate constant $\mathrm{k}_{\mathrm{r}}{ }^{15}$. With any excess [docetaxel], every empty site is rapidly filled by docetaxel (Fig. 1d, Left Inset). The Flutax-2 $\mathrm{k}_{\mathrm{r}}$ determined here was $8.9 \pm 0.3 \times 10^{-3} \mathrm{~s}^{-1}$ at 2 and $20 \mu \mathrm{M}$ docetaxel (cf. ${ }^{15}$ ).

Cyclostreptin was very different. Although $2-40 \mu \mathrm{M}$ cyclostreptin fully displaced bound Flutax-2 following monoexponential kinetic curves (Fig. 1d), the observed dissociation rate constant $\left(k_{o b s}\right)$ increased with [cyclostreptin] until it equaled the $k_{r}$ of Flutax-2 obtained with docetaxel (Fig. 1d, Right Inset). This indicates that the overall reaction is limited by the rate of cyclostreptin binding to microtubules. The explanation that cyclostreptin binds relatively slowly, with rebinding of free Flutax-2, is inconsistent with the monoexponential kinetic curves. These indicate a constant reaction rate, while increasing [Flutax-2] should cause the apparent $k_{r}$ to decrease over time.

An alternative explanation is that cyclostreptin binds to the Flutax-2microtubule complex with cyclostreptin binding inducing Flutax-2 dissociation:

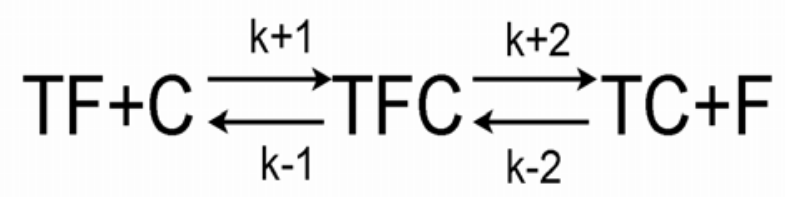

where $\mathrm{T}$ represents the taxoid site in microtubules, $\mathrm{C}$ is cyclostreptin, and F is Flutax2. Then the observed reaction step would be the second, with monophasic kinetics at 
steady state ([TCF] constant during the experiment), with the rate dependent on [cyclostreptin]. Curve fitting ${ }^{16}$ to this kinetic model yielded a $k_{+2}$ value of $0.008 \pm 0.002$ $\mathrm{s}^{-1}$, in agreement with the $0.006 \mathrm{~s}^{-1}$ value for Flutax-2 dissociation at $25{ }^{\circ} \mathrm{C}$ with docetaxel ${ }^{15}$, a negligible $k_{-1}$ value and a $k_{+1}$ value of $350 \pm 20 \mathrm{M}^{-1} \mathrm{~s}^{-1}$. These values indicate an irreversible reaction has occurred.

Cellular effects of cyclostreptin. Competition experiments of cyclostreptin with Flutax-2 were performed with unfixed cytoskeletons from PtK2 cells. When cyclostreptin or paclitaxel was added to cytoskeletons with bound Flutax-2, both compounds displaced Flutax-2. PtK2 cytoskeletons preincubated with paclitaxel, but not those preincubated with cyclostreptin, bind Flutax-2 (Fig. 2a-c), showing irreversible binding of cyclostreptin to the cytoskeletons.

Similarly, there were differences in the effects of cyclostreptin and paclitaxel on cellular microtubules. There was partial recovery of the microtubule network in paclitaxel-treated PtK2 cells, but the effects of cyclostreptin were irreversible. Cells were incubated $7 \mathrm{~h}$ with 2 or $5 \mu \mathrm{M}$ cyclostreptin or $10 \mu \mathrm{M}$ paclitaxel, extensively washed and incubated 16 or $48 \mathrm{~h}$ longer. Untreated cells had typical microtubule networks after 7 or $23 \mathrm{~h}$ (Fig. $\mathbf{2 d , g}$ ) and normal nuclei. Cells incubated $7 \mathrm{~h}$ with ligand had microtubule bundles (Fig. 2e,f) a small percentage of them were micronucleated ( $4 \%$ of the cells) or arrested in mitosis with multiple asters.

After washing and another $16 \mathrm{~h}$ in culture, the cyclostreptin effect progressed: the bundles were unchanged (Fig. 2h), and cells with micronucleation or multipolar spindles increased in number to about $70 \%$. With paclitaxel, microtubules reverted to a normal appearance (Fig. 2i), although the number of micronucleated cells had increased to about $70 \%$. After a $48 \mathrm{~h}$ recovery, cyclostreptin-treated cells had 
somewhat sparser microtubule bundles but an unchanged number of micronucleated cells. After $48 \mathrm{~h}$ without drug, paclitaxel-treated cells continued to recover, with micronucleation reduced to about $40 \%$.

The PtK2 cells were examined for DNA content by flow cytometry (Supplementary Table 1), and these data also indicated a larger recovery following paclitaxel versus cyclostreptin treatment, with a larger population of $\mathrm{G} 2+\mathrm{M}$ cells persisting following cyclostreptin treatment.

We tested the cytotoxicity of cyclostreptin in paclitaxel-resistant and nonresistant carcinoma cell lines (Table 2). Cyclostreptin was around 40 times less active than paclitaxel in non-resistant lines, while the relative resistance observed in PTX10 and PTX22 was reduced from 27 and 17 for paclitaxel to 5 and 1.3 for cyclostreptin. In the MDR line, however, cyclostreptin was highly active, with a resistance factor of 1.2, as compared with 600-900 for paclitaxel and docetaxel.

Cell cycle analysis was performed in PtK2, A549, A2780 and A2780/AD cells incubated for $24 \mathrm{~h}$ with paclitaxel or cyclostreptin. The lowest concentrations that gave maximal accumulation of cells in the $\mathrm{G} 2+\mathrm{M}$ phase were $0.5 \mu \mathrm{M}, 20 \mathrm{nM}, 15 \mathrm{nM}$, and $1 \mu \mathrm{M}$, respectively, for paclitaxel, while for cyclostreptin this concentration was $100 \mathrm{nM}$ in the four cell lines. Thus, cyclostreptin was more active than paclitaxel in the cell lines least sensitive to paclitaxel (PtK2 and A2780/AD) (Supplementary Table 2).

Characterization of cyclostreptin binding site by MS. MS chromatograms of digested tubulin samples, derived from untreated (Fig. 3a) or cyclostreptin-treated (Fig. 3b top) microtubules showed differential, intense peaks corresponding to tubulin peptides producing a cyclostreptin-derived fragment ion at $\mathrm{m} / \mathrm{z} 249.0$ (see 
Materials and Methods; Peaks 1-2 and 3-7 in the trypsin- and chymotrypsin-digested samples, respectively). These signals were absent in control samples (Fig. 3a, black arrows). MS/MS-based peptide sequencing (Supplementary Fig. 1) of Peaks 1 to 7 demonstrated that all peptide sequences map into residues $219-243$ of $\beta$-tubulin (Fig. 3c). This sequence contains part of the taxoid site ${ }^{7}$. Peaks 1 and 2 correspond, respectively, to oxidized and non-oxidized, cyclostreptin-modified LTTPTYGDLNHLVSATMSGVTTCLR. The cyclostreptin-tagged peptide appeared in triply and quadruply charged form in the analyzed mass range. Peaks 3 to 7 correspond to the sequences indicated (Fig. 3c). A comprehensive study of the fragmentation spectrum from the parent ion corresponding to Peak 2 revealed the peptide spanning residues $219-243$ as the binding site for cyclostreptin (Supplementary Fig. 1a), but the $>3 \mathrm{kDa}$ size of this peptide made the precise modification site uncertain. Analysis of the fragmentation spectrum from the peptides spanning residues 220-230 (Peak 5) (Supplementary Fig. 1b) and 220-235 (Peak 7) revealed that Thr220 formed a covalent bond with cyclostreptin. Analysis of the fragmentation spectra from the ions corresponding to Peaks 3,4 and 6 (Supplementary Fig. 1c) demonstrated a second modification site, Asn228. No doubly-labeled peptides were found, so the covalent reactions with Thr220 and Asn228 are mutually exclusive. Although relative areas measured from chromatographic peaks corresponding to chymotryptic peptides from cyclostreptintreated samples (Fig. 3b, right) indicate a more extensive reaction with asparagine versus threonine, ionization of chromatographically separated peptides is significantly influenced by the composition of the pool of accompanying peptides eluted at a given retention time. The relative reactivity of the two amino acid residues thus cannot be determined reliably by MS analysis. 
However, the chromatographic signal corresponding to LTTPTYGDLNHLVSATMSGVTTCLR showed that there is a 1:1 stoichiometry for the interaction of cyclostreptin with $\alpha \beta$-tubulin in microtubules (Supplementary Fig. 2). In the extracted ion chomatography $(E I C)$ for triply-charged ions, this peptide was present in one of two alternative forms. Without cyclostreptin, unmodified LTTPTYGDLNHLVSATMSGVTTCLR $\quad(m / z \quad 884.4 \quad$ Da) was observed. When cyclostreptin was included in the reaction mixture, only the corresponding peptide with one cyclostreptin added (m/z 1017.6 Da) was observed. Thus, all $\beta$-tubulin subunits in the microtubules were modified by addition of a single cyclostreptin.

Similar experiments were performed under nonpolymerizing reaction conditions, where either the heterodimer or small oligomeric species predominate, depending on the $\mathrm{Mg}^{2+}$ concentration. Analysis of precursor ion scanning experiments demonstrated the presence of weak chromatographic Peaks 1, 2 and 5, but not Peaks 3, 4, 6 and 7. Thus, only formation of small amounts of the Thr220 adduct in nonpolymerized tubulin was detectable (from peak intensity, less than $5 \%$ with oligomeric tubulin and less than $0.5 \%$ with heterodimeric tubulin). To verify these results and gain sensitivity, samples were also analyzed by multiple reaction monitoring (MRM) scan mode, fixing the Q3 quadrupole for the detection of the diagnostic ion at $\mathrm{m} / \mathrm{z} 249.0 \mathrm{Da}$. lons at $\mathrm{m} / \mathrm{z} 1017.6,636.8,816.4$, and 779.4 (at the $\mathrm{m} / \mathrm{z}$ of chromatographic Peaks 2, 4, 5, and 6) were isolated and fragmented. Only precursors and fragmentation spectra from ions corresponding to Peaks 2 and 5 were detected (Fig. 3b bottom), again unambiguously documenting the Thr220 modification. No evidence was found for ions corresponding to Peaks 4 and 6, which contain the modified Asn228. The MRM experiments confirmed that the modified 
peaks were 10 -fold more intense in peptides derived from oligomeric versus dimeric tubulin samples.

To be sure the Thr220 modification found in microtubules had not occurred in oligomers prior to microtubule assembly, microtubules stabilized by paclitaxel at a concentration (22 $\mu \mathrm{M}$ paclitaxel, $20 \mu \mathrm{M}$ tubulin) much greater than the $1 \mu \mathrm{M}$ drug required to supress microtubule dynamics ${ }^{17}$ were incubated with excess cyclostreptin. This results in cyclostreptin displacing paclitaxel from the preformed microtubules. Since paclitaxel binding to microtubules is reversible, cyclostreptin should bind to transiently unoccupied sites, progressively displacing the bound paclitaxel. Therefore the very same labeling would be expected, unless the Thr220 modification occurred in oligomers prior to microtubule assembly, in which case only labeling at Asn228 should be observed. In MRM experiments, ions at $\mathrm{m} / \mathrm{z}$ 1017.6, 636.8, 816.4, and 779.4 (Peaks 2, 4, 5 and 6) were detected, while in precursor ion scanning experiments, using the ion at $\mathrm{m} / \mathrm{z} 249.0$ as the diagnostic signal, we also found tubulin-derived peptides corresponding to Peaks 3 and 7 . Thus, the modifications at Thr220 and Asn228 were unambiguously documented again. We therefore conclude that the Thr220 modification must occur during the binding of cyclostreptin to microtubules.

Cyclostreptin-labeling of cellular tubulin. To verify that the tubulin-cyclostreptin adduct is formed in treated cells, A549 cells were incubated $24 \mathrm{~h}$ with $1 \mu \mathrm{M}$ cyclostreptin or DMSO, and their cytoskeletons were isolated and digested with trypsin. The digestion mixture was analyzed by HPLC, with detection by MRM scan mode for the $\mathrm{m} / \mathrm{z}$ of the cyclostreptin-labeled form of LTTPTYGDLNHLVSATMSGVTTCLR (not shown). A peak at the expected retention 
time for the labeled peptide was detected, indicating formation of the adduct in living cells.

To determine the proportion of cellular tubulin that had reacted with cyclostreptin, tubulin from cyclostreptin-treated (24 h) and from control A549 cells was purified using a one-step ion-exchange procedure. The method yields tubulin of $>90 \%$ purity (Supplementary Fig. 3a) suitable for MS procedures. Following treatment with trypsin, the reaction mixture was subjected to HPLC with analysis in the MRM scan mode with Q1 scanning for the $\mathrm{m} / \mathrm{z}$ of unmodified and cyclostreptinlinked LTTPTYGDLNHLVSATMSGVTTCLR (Peak 2) and Q3 scanning for a common peptide in the $y$ fragmentation series of both labeled and non-labeled peptide (Fig. 3d). While tubulin from control cells (black filled chromatogram) showed only one peak with a $\mathrm{m} / \mathrm{z}$ of 884.4 , which corresponded to triply-charged unmodified peptide, tubulin from cyclostreptin-treated cells showed two peaks. The major peak, with $\mathrm{m} / \mathrm{z}$ of 1017.6, corresponded to the triply-charged peptide crosslinked to cyclostreptin, and the minor peak was identical with the unmodified peptide from control cells. The areas of the peaks derived from tubulin from control and from cyclostreptin-treated cells indicated that about $60 \%$ of the tubulin from treated cells contained the adduct. About $60 \%$ of tubulin in paclitaxel-treated $1 \mathrm{~A} 9$ cells forms polymer ${ }^{18}$, not very different from the proportion of tubulin that reacts with cyclostreptin in A549 cells. This suggested near total formation of cyclostreptin adduct in the microtubules of treated A549 cells.

Both Thr220 and Asn228 were covalently modified in the tubulin from cyclostreptin-treated cells. The isolated tubulin was digested with chymotrypsin, and the digest was subjected to HPLC, with analysis in the MRM mode with Q1 scanning for signals at $\mathrm{m} / \mathrm{z}$ 636.8, 816.4 and 779.4 (corresponding to Peaks 4,5 (both 
containing the Thr220 modification) and 6 (containing the Asn228 modification)) and Q3 scanning for the 249.0 signal, diagnostic for the covalent reaction with cyclostreptin (Supplementary Fig. 3b). The HPLC trace showed the presence of the three peaks, confirming that reactions had occurred with both amino acids.

The strained olefin of cyclostreptin is essential for its activity. The chemical structure of cyclostreptin (Fig. 1a) is characterized by a highly strained olefin (C2C17). C17 and the lactone carbonyl $\mathrm{C} 1$ have been proposed as electrophilic sites that could react covalently with proteins ${ }^{19}$.

In principle, cyclostreptin could undergo nucleophilic attack at either of these carbons (Scheme 1), resulting in an increase in mass of the peptide exactly coincident with the mass of cyclostreptin. Either an acylation reaction of the lactone through nucleophilic attack on C1 (Scheme 1a) or a simple addition of nucleophile to C17, with concomitant release of strain due to the $\mathrm{C} 2-\mathrm{C} 17$ bridgehead alkene, are reasonable modes of covalent bond formation (Scheme $\mathbf{1 b}$ top). A third possibility is an addition-elimination sequence of the nucleophile at the $\mathrm{C} 2-\mathrm{C} 17$ bond. This would result in the formation of a 9-membered ring alcohol (Scheme 1b bottom). Modification of other reactive groups of cyclostreptin, with the exception of the unstrained C10-C11 olefin bond, would imply the loss of a water molecule.

An extensive study of the reactivity of the strained olefin of cyclostreptin with model nucleophiles ${ }^{20}$ led to the conclusion that the reaction is a simple addition of the nucleophile to $\mathrm{C} 17$ driven by strain release. Generally, the reaction was quantitative, as determined by NMR analysis of reaction mixtures, and no evidence for a 9member ring product was found. Both Thr and Asn of the peptide have nucleophilic side chains that might attack cyclostreptin at $\mathrm{C} 17$ by an analogous addition reaction. 
In order to confirm that the reaction site is the $\mathrm{C} 2-\mathrm{C} 17$ olefin, two cyclostreptin analogues were prepared. First, the double bond was epoxidized (Fig. 1a), yielding an inactive compound ${ }^{21}$ (Flutax-2 binding unaltered; no activity against cultured cells (Table 2)). Second, the C2-C17 olefin bond was reduced (Fig. 1a), again eliminating biological activities of cyclostreptin (no effect on cell proliferation (Table 2) or Flutax-2 binding; no covalent adduct formed with microtubules as determined by MS). While the epoxide is potentially electrophilic at $\mathrm{C} 1, \mathrm{C} 2$ and $\mathrm{C} 17$, reduced cyclostreptin no longer has the strained olefin, with only $\mathrm{C} 1$ being a potential electrophile. However, the inactivity of these two analogues buttresses the conclusion that it is the strained olefin of cyclostreptin that reacts with tubulin through a simple addition at $\mathrm{C} 17$, as previously demonstrated with model nucleophiles ${ }^{20}$.

Molecular modeling. The complex of cyclostreptin with Thr220 was modeled in silico by forming a covalent bond with its side chain oxygen (Supplementary Fig. 4). The resulting adduct was optimized with MacroModel, identifying a possible binding site formed by residues $217-223$ and $277-279$ from $\beta$-tubulin, $323-328$ from the adjacent $\alpha$-tubulin, 95-99 from $\beta$-tubulin of a neighboring protofilament, and 128-132 from $\alpha$-tubulin of a neighboring protofilament (Supplementary Fig. 5). Assuming this complex represents that observed experimentally, there are two additional hydrogen bonding interactions that would help stabilize the complex: the hydroxyl group at C15 with Arg278 and the C1 carbonyl group with Thr221. This adduct is further stabilized by hydrophobic contacts with a non-polar region of the adjacent $\alpha$-tubulin (GIn128Leu132).

Cyclostreptin also reacts with with Asn228. The atoms of the backbone of this amino acid are located at the lumenal taxoid site, while the side chain forms two 
strong hydrogen bonds with the exchangeable nucleotide. Therefore, either the position of the Asn228 sidechain in microtubules differs from its position in $\mathrm{Zn}$ induced sheets $^{7,8}$, or cyclostreptin causes the displacement of the Asn228 side chain by forming a non-covalent pre-complex at the paclitaxel site, facilitating a subsequent reaction of cyclostreptin with the Asn228 side chain amide.

\section{DISCUSSION}

Cyclostreptin contains two electrophilic functional groups: a strained bridgehead olefin and a lactone carbonyl group. Other natural products containing such moieties react covalently with nucleophilic residues in protein active sites, causing biological effects 22,23 .

The biological activities of cyclostreptin overwhelmingly favor microtubules as the target of the compound. However, it is not a classical taxoid site ligand. Despite strongly displacing taxoid site ligands from microtubules, it only weakly induces microtubule assembly ${ }^{5,6,13}$.

Our results showed that cyclostreptin is the first MSA that binds covalently to microtubules and the first taxoid site ligand whose binding to dimeric tubulin has been detected. MS analysis showed that in microtubules cyclostreptin formed a covalent bond with either Thr220 or Asn228. In unpolymerized tubulin, only Thr220 formed a bond with cyclostreptin, and this covalent interaction was much less extensive than the reaction with microtubules. We also demonstrated that both crosslinks to $\beta$-tubulin form in cyclostreptin-treated cells. Covalent bond formation explains the unusual biochemical properties of cyclostreptin, such as the distinct requirement for higher temperatures for assembly induction and binding to polymer and the high stability of cyclostreptin polymer to disassembly at $0{ }^{\circ} \mathrm{C}^{6}$. Once 
covalently bound to microtubules, cyclostreptin cannot dissociate, and the microtubules cannot disassemble, being more stable than untreated control and paclitaxel-induced microtubules.

Similarly, PtK2 cellular microtubule bundles induced by cyclostreptin were more stable than those induced by paclitaxel. Although cyclostreptin is $1 / 40$-th as cytotoxic as paclitaxel, it retains its activity in cells resistant to paclitaxel by overexpression of P-gp or expression of mutant $\beta$-tubulins, becoming more potent than paclitaxel in the former case. Therefore, formation of a covalent tubulin adduct can be a mechanism to escape these mechanisms of resistance, at least in cultured cells. While agents that react covalently with specific targets can be too toxic for use in human patients ${ }^{24}$, some covalently reactive compounds are successfully used clinically. Examples are the antiobesity drug tetrahydrolipstatin, which reacts with pancreatic lipase ${ }^{25}$, and the anticancer platinum agents, which react with DNA ${ }^{26}$. In the MDR A2780/AD cells, the covalent adduct of cyclostreptin with tubulin could escape the pump. With the tubulin mutants, cyclostreptin affinity for the altered tubulin(s) might be modified. Alternatively, the longer time frame involved in cell culture studies could still lead to irreversible tubulin inactivation by covalent bond formation, even if the tubulin(s) have reduced affinity for cyclostreptin. In summary, since the formation of the adduct is a kinetically controlled, irreversible process, resistant tumor cells can not escape the effect of cyclostreptin by reduction of affinity for the target or enhancing drug efflux, which suggests that the design of ligands that covalently react with the taxoid site or other targets might be an effective way to address drug resistance.

The discovery of the covalent reactions of cyclostreptin with tubulin and microtubules provides new insights into two obscure aspects of the mechanism of 
binding of ligands to the taxoid site. First, modeling of paclitaxel-stabilized zinc sheet protofilaments into a microtubule structure led to the conclusion that the taxoid site was on $\beta$-tubulin adjacent to the microtubule lumen ${ }^{7,8}$. In contrast, kinetic measurements, effects of MAPs and antibody binding ${ }^{10,11,15}$ indicated an easily accessible site, most logically on the outer microtubule surface. To reconcile these observations, we proposed an exterior taxoid binding site where ligands bound initially, prior to transfer to the lumenal site $^{10}$. The two sites could not be occupied simultaneously because of the observed 1:1 binding stoichiometry ${ }^{\mathrm{b}}$. The proposed site was at pore type I, including $\beta$-tubulin residues Phe214, Thr220, Thr221 and Pro222 in the $\mathrm{H} 6-\mathrm{H} 7$ loop $^{10}$. We have now shown that the taxoid site agent cyclostreptin reacts covalently with Thr220 at the proposed pore type I site and with Asn228, a residue at the lumenal site.

The proposed two-step mechanism is consistent with the two-step kinetics of binding of fluorescent taxoids to microtubules ${ }^{15}$. Step one is a bimolecular reaction with a micromolar $K_{d}$ and a $k_{f}$ about $10^{6} \mathrm{M}^{-1} \mathrm{~s}^{-1}$, most consistent with a diffusion limited reaction involving an exposed site on the microtubule surface, such as the pore type I site containing Thr220. Step two would be a monomolecular reaction with a $\mathrm{K}_{\text {eq }} \approx 20$, which indicates that about $5 \%$ of the bound ligand would remain at the external site. The data obtained with the fluorescent taxoids indicated the first step involves binding of the taxoid moiety without immobilization of the fluorescein group, since there was no increase in fluorescence anisotropy. This is consistent with the taxoid moiety binding at Thr220, and, with longer linkers, the fluorescein moiety was fully accessible to antibodies ${ }^{11}$.

The hypothesis that binding at the pore type I site, as manifested by the reaction of cyclostreptin with Thr220, precedes binding of taxoid site agents to the 
lumenal site is supported by the fact that covalent binding of cyclostreptin to microtubules abolished subsequent binding of every taxoid site agent examined (Table I; Fig. 1c). In the Flutax-2 experiment, $50 \mathrm{nM}$ taxoid was incubated with up to $1 \mu \mathrm{M}$ taxoid sites preincubated with cyclostreptin, and Flutax-2 binding was completely abolished. Even if $1 \%$ of the taxoid sites had been accessible to Flutax-2, a change of in the fluorescence anisotropy signal would have been detectable. Cyclostreptin reacts with tubulin in microtubules in a 1:1 proportion, and thus such microtubules, as the MS data show, would have $\alpha \beta$-dimers with the $\beta$-tubulin modified at both Thr220 and Asn228. While dimers modified at Asn228 would not have bound Flutax-2 because the taxoid site was at least partially occupied by the cyclostreptin moiety, one can imagine other routes to the lumenal taxoid site when the dimers were modified at Thr220. For example, Flutax-2 could have reached the lumen through type II pores or through microtubule ends. The failure to detect even low levels of Flutax-2 binding argues that an initial interaction at the pore type I site is an obligatory route to the lumenal site.

Second, previous studies ${ }^{12,27}$ showed that paclitaxel binds avidly to microtubules but not to $\alpha \beta$-heterodimers. However, paclitaxel and other taxoid site agents will initiate assembly in tubulin solutions in which no microtubules (i.e., presumptive binding sites) exist. It was proposed that paclitaxel might bind to tubulin oligomers $^{28}$, leading to assembly under otherwise unfavorable conditions. In the present work, we find a low level of cyclostreptin covalent reactivity with Thr220 in dimeric and oligomeric tubulin, under conditions in which microtubule assembly is prevented by keeping the free $\mathrm{Mg}^{+2}$ concentration lower than that required to assemble microtubules with $20 \mu \mathrm{M}$ tubulin ${ }^{12}$. This demonstrates a MSA binding site in non-assembled tubulin. No reaction with Asn228 was observed, indicating the 
lumenal site is not present without microtubule formation. The binding affinity of MSAs for the site containing Thr220 in $\alpha \beta$-heterodimers/oligomers must be very low, but binding to this site could initiate an assembly reaction, with creation of the higher affinity lumenal site and stabilization of nascent polymer. The irreversible covalent reaction of cyclostreptin with Thr220 allowed trapping of the binding complex and detection of this evanescent species.

The assembly process could involve transformation of some elements from being components of the external site into becoming part of the lumenal site. However, the Thr220 cyclostreptin adduct forms under all reaction conditions examined, including in preformed, paclitaxel-stabilized microtubules following paclitaxel displacement by cyclostreptin. Thus, the external pore type I site must also exist to some extent after assembly. Overall, the data presented here demonstrate the existence of an MSA binding site in unassembled tubulin and support the hypothesis that taxoids reach the lumenal site through transient binding to the pore type I site.

\section{METHODS}

Previously described methodologies. Previous papers provide details for preparation of tubulin ${ }^{29}$, cyclostreptin ${ }^{20}$, epoxidized cyclostreptin ${ }^{21}$, glutaraldehydestabilized microtubules and quantitation of their taxoid sites ${ }^{10,14}$, electron microscopy, $\left[{ }^{3} \mathrm{H}\right]$ paclitaxel binding studies ${ }^{6}$, cytotoxicity assays and cell cycle analysis ${ }^{5}$ and culture and immunofluorescence analysis of PtK2 potoroo kidney cells ${ }^{30}$. Human ovarian carcinoma 1A9, PTX10, PTX22 ${ }^{18}$ and lung carcinoma A549 were cultured as described $^{5} ; A 2780$ and $A 2780 / A D$ (P-gp overexpressing) cells were grown in the 
same medium supplemented with 0.25 units $\mathrm{ml}^{-1}$ of bovine insulin. Binding of $\left[{ }^{3} \mathrm{H}\right]$ discodermolide and $\left[{ }^{14} \mathrm{C}\right]$ epothilone $\mathrm{B}$ was measured as was $\left[{ }^{3} \mathrm{H}\right]$ paclitaxel.

Ligands. See Supplementary Methods for preparation of reduced cyclostreptin and information about other ligands.

Binding of cyclostreptin to microtubules. Samples containing crosslinked microtubules (35 $\mu \mathrm{M}$ taxoid sites) and $30 \mu \mathrm{M}$ cyclostreptin were incubated for 30 min at $25^{\circ} \mathrm{C}$ in $3.4 \mathrm{M}$ glycerol, $10 \mathrm{mM} \mathrm{NaP}_{\mathrm{i}}, 1 \mathrm{mM} \mathrm{EGTA}$ and $6 \mathrm{mM} \mathrm{MgCl}, \mathrm{pH} 6.7$ (GAB), plus $0.1 \mathrm{mM}$ GTP. Samples were processed and extracted, with each organic extract residue dissolved in $200 \mu \mathrm{l}$ of $\mathrm{CH}_{3} \mathrm{OH}^{14}$. For uncrosslinked microtubules, samples were prepared using $20 \mu \mathrm{M}$ tubulin plus $25 \mu \mathrm{M}$ cyclostreptin in GAB, 1 mM GTP.

Ligands reversibly bound to pelleted polymer or in the supernatant were detected by HPLC-MS (Supplementary Methods).

Inhibition of binding of Flutax-2 to microtubules. Crosslinked microtubules (60 $\mu \mathrm{M})$ were incubated with $66 \mu \mathrm{M}$ cyclostreptin, epoxidized cyclostreptin or reduced cyclostreptin or DMSO overnight at $22{ }^{\circ} \mathrm{C}$ in GAB, $0.1 \mathrm{mM}$ GTP and dialyzed for $5 \mathrm{~h}$ against the same solution. Flutax-2 $(50 \mathrm{nM})$ was titrated with these preparations, and $\mathrm{K}_{\mathrm{a}}$ 's for Flutax-2 binding were calculated $^{14}$.

Competition of cyclostreptin with Flutax-2 was also performed with native PtK2 cytoskeletons stained 10 min with $0.2 \mu \mathrm{M}$ Flutax-2, washed (8x) in two wells with $2 \mathrm{ml}$ of $10 \mathrm{mM}$ Pipes, $1 \mathrm{mM}$ EGTA, $1 \mathrm{mM} \mathrm{MgCl}_{2}, 4 \%$ polyethyleneglycol, $\mathrm{pH} 6.8$ and incubated 15 min with $100 \mu \mathrm{M}$ cyclostreptin or paclitaxel or DMSO. After washing 
again, coverslips were mounted and examined. Cytoskeletons were also preincubated with $10 \mu \mathrm{M}$ cyclostreptin or paclitaxel or DMSO for $10 \mathrm{~min}$, washed, stained with $0.2 \mu \mathrm{M}$ Flutax-2 and visualized.

Flutax-2 dissociation kinetics. The dissociation kinetics of Flutax-2 from microtubules was measured by fluorescence anisotropy (Supplementary Methods).

Purification of tubulin from cells. Five $175 \mathrm{~cm}^{2}$ flasks with a monolayer of A549 cells were incubated for $24 \mathrm{~h}$ with $1 \mu \mathrm{M}$ cyclostreptin or DMSO. Cells were removed with PBS, 0.5 mM EDTA, washed with PBS and harvested by centrifugation. The cell pellet $(1 \mathrm{ml})$ was resuspended in $1 \mathrm{ml}$ of $10 \mathrm{mM} \mathrm{NaP}, 1 \mathrm{mM} \mathrm{MgCl}, 0.1 \mathrm{mM} \mathrm{GTP}$, $0.24 \mathrm{M}$ sucrose, $\mathrm{pH} 7.0$ and stored in liquid nitrogen. After thawing the cells, DTT and GTP to $1 \mathrm{mM}$ were added, and the cells were hand-homogenized in glass. The homogenate was centrifuged $\left(38,000 \mathrm{rpm}, 1 \mathrm{~h}, 4{ }^{\circ} \mathrm{C}\right.$, TLA 100.4 rotor in an Optima TLX ultracentrifuge). The supernatant was adjusted to $0.4 \mathrm{M} \mathrm{KCl}$ and loaded onto a High-Trap DEAE Fast Flow $1 \mathrm{ml}$ column in a FPLC system (GE Healthcare) developed at $1 \mathrm{ml} \mathrm{min}^{-1}$. Unbound protein was removed with $5 \mathrm{ml}$ of $10 \mathrm{mM} \mathrm{NaP}, 1$ $\mathrm{mM} \mathrm{MgCl} 2,0.1 \mathrm{mM}$ GTP, $0.4 \mathrm{M} \mathrm{KCl}, \mathrm{pH}$ 7.0. Bound protein was eluted with $0.8 \mathrm{M}$ $\mathrm{KCl}$ in the same buffer and desalted into $10 \mathrm{mM} \mathrm{NaP}_{\mathrm{i}}, 1 \mathrm{mM} \mathrm{MgCl}, 0.1 \mathrm{mM} \mathrm{GTP}, \mathrm{pH}$ 7.0 with a Hitrap Desalting column. The tubulin was $90 \%$ pure, as determined by SDS-PAGE. The tubulin was stored in liquid nitrogen, following addition of $0.24 \mathrm{M}$ sucrose.

Protein digestion and sample preparation for MS analysis. Tubulin control, cyclostreptin-treated, and reduced cyclostreptin-treated samples were prepared 
using native microtubules, polymerized for $30 \mathrm{~min}$ at $37^{\circ} \mathrm{C}$ in $\mathrm{GAB}, 1 \mathrm{mM}$ GTP (200 $\mu \mathrm{l}, 20 \mu \mathrm{M}$ tubulin with $2.5 \% \mathrm{DMSO}$ or $25 \mu \mathrm{M}$ drug). In another sample, $20 \mu \mathrm{M}$ tubulin in GAB, $1 \mathrm{mM}$ GTP was assembled with $22 \mu \mathrm{M}$ paclitaxel for $15 \mathrm{~min}$ at $37{ }^{\circ} \mathrm{C}(>97 \%$ assembly ${ }^{5}$ ) and incubated for another $45 \mathrm{~min}$ at $37^{\circ} \mathrm{C}$ following addition of $50 \mu \mathrm{M}$ cyclostreptin to displace bound paclitaxel. Morphology of polymers was always verified to be microtubules. Microtubules were harvested by centrifugation as described above. Pellets were washed twice with water and suspended in $200 \mu$ of $50 \mathrm{mM} \mathrm{NH}_{4} \mathrm{HCO}_{3}, 12 \mathrm{mM}$ EDTA, 0.01\% SDS, pH 7.6. Unassembled tubulin samples were prepared using $20 \mu \mathrm{M}$ GTP-tubulin in $10 \mathrm{mM} \mathrm{NaP}, 1 \mathrm{mM}$ EDTA, $0.1 \mathrm{mM}$ GTP, $\mathrm{pH} 7.0$ without (dimeric tubulin) or with $1.5 \mathrm{mM} \mathrm{MgCl}_{2}$ (oligomeric tubulin) and $2.5 \%$ DMSO or $25 \mu \mathrm{M}$ cyclostreptin. Samples were centrifuged as above to remove aggregates, $20 \mu \mathrm{l}$ was diluted $1: 1$ into $50 \mathrm{mM} \mathrm{NH}_{4} \mathrm{HCO}_{3}$ and digested with trypsin (1 $\mu \mathrm{g}$ sequencing grade, Promega, $\left.2 \mathrm{~h}, 37^{\circ} \mathrm{C}\right)$ or chymotrypsin $(1 \mu \mathrm{g}$ Type VII, TLCK treated, Sigma, $1 \mathrm{~h}, 25^{\circ} \mathrm{C}$ ). Reaction mixtures were dried in vacuo and, for analysis, dissolved in $5 \% \mathrm{CH}_{3} \mathrm{CN}, 0.5 \% \mathrm{CH}_{3} \mathrm{COOH}$.

Nano-HPLC and tandem triple quadrupole MS analysis of peptides. Peptides from control, cyclostreptin-treated and reduced cyclostreptin-treated samples were analyzed with a Supelco $\mathrm{C} 18$ nano-column, developed with a $\mathrm{CH}_{3} \mathrm{CN}$ gradient and eluted into a Protana nanospray ion-source. Ions were analyzed as described in Supplementary Methods.

MRM of selected cyclostreptin-bound peptides derived from unassembled tubulin and tubulin isolated from cells. (Supplementary Methods). 
Detection of cyclostreptin labeling of tubulin by nano-HPLC coupled to threedimensional ion-trap MS. Tryptic peptides from control and cyclostreptin-treated microtubules were injected onto a Supelco $\mathrm{C} 18$ nano-column. $\mathrm{A} \mathrm{CH}_{3} \mathrm{CN}$ gradient was used to elute peptides to a PicoTip ${ }^{\mathrm{TM}}$ emitter nano-spray needle (New Objective) for real-time ionization and peptide fragmentation on an Esquire HCT ion-trap (Bruker Daltoniks) mass spectrometer (Supplementary Methods (Supplementary Fig. 6)).

MS data analysis. All chromatograms and MS/MS spectra from the $4000 \mathrm{Q}$ Trap system were analyzed with Analyst 1.4.1 (Applied Biosystems). All HPLCMS/MS experiments were repeated with five independent samples. Chromatographic and MS data from the 3D ion-trap system were processed by DataAnalysis 3.3 (Bruker Daltoniks).

Molecular modeling of cyclostreptin binding to tubulin. The simulations needed to investigate the covalent binding of cyclostreptin were performed with Macromodel 8.5 over a model of pore type I built from the structure 1JFF in the PDB.

\section{Footnotes}

${ }^{a} W e$ use the sequence nomenclature of ref. 7 . These two residues in $\beta$-tubulin are actually at positions 218 and 226 , respectively ${ }^{31}$.

'Similar stoichiometry has been found for discodermolide (M. Edler, unpublished data) and epothilone $A$ and epothilone $B$ binding ${ }^{14}$. 
Address correspondence to: J. Fernando Díaz, Department of Protein Science, Centro de Investigaciones Biológicas, CSIC, Ramiro de Maeztu, 9, 28040 Madrid, Spain. Phone: 34-918373112, ext.4269. Fax: 34-915360432. E-mail: fer@cib.csic.es Address requests for materials: Christopher D. Vanderwal, Department of Chemistry, University of California, Irvine, CA 92697, USA. Phone: 1-949-824-6702. E-mail: $\underline{c d v @ u c i . e d u}$

\section{Acknowledgements}

The authors thank J. Vilarrasa for helpful discussions, P. Lastres for his help with flow cytometry, and Matadero Madrid Norte S.A. and José Luis Gancedo S.L. for providing calf brains for tubulin purification. This work was supported in part by grant BFU2004-00358 from Ministerio de Educación y Ciencia and 200520M061 from Comunidad Autonoma de Madrid to JFD. RMB was supported by a MECD FPU fellowship.

\section{Author Contributions}

R.M.B., performed research; E.C., performed research; I.B: designed and performed research; O.P., performed research; M.C.E., performed research; R.M., performed research; G.C., performed research; C.D.V., contributed materials and performed research; B.W.D., contributed materials and edited the manuscript; E.J.S, contributed materials; J.A.L., interpreted data; J.M.A., designed research, interpreted data and edited the manuscript; E.H., interpreted data and wrote the paper; J.F.D., designed research, performed research, interpreted data and wrote the paper. 


\section{REFERENCES}

1. Jordan, M. A. \& Wilson, L. Microtubules as a target for anticancer drugs. Nat. Rev. Cancer. 4, 253-65 (2004).

2. Jordan, M. A., Toso, R. J., Thrower, D. \& Wilson, L. Mechanism of mitotic block and inhibition of cell proliferation by taxol at low concentrations. Proc. Natl. Acad. Sci. U S A 90, 9552-6 (1993).

3. Schiff, P. B., Fant, J. \& Horwitz, S. B. Promotion of microtubule assembly in vitro by taxol. Nature 277, 665-7 (1979).

4. Diaz, J. F. \& Andreu, J. M. Assembly of purified GDP-tubulin into microtubules induced by taxol and taxotere: reversibility, ligand stoichiometry, and competition. Biochemistry 32, 2747-55 (1993).

5. Buey, R. M. et al. Microtubule interactions with chemically diverse stabilizing agents: Thermodynamics of binding to the paclitaxel site predicts cytotoxicity. Chem. Biol. 12, 1269-1279 (2005).

6. Edler, M. C. et al. Cyclostreptin (FR182877), an antitumor tubulin-polymerizing agent deficient in enhancing tubulin assembly aespite its high affinity for the taxoid site. Biochemistry 44, 11525-11538 (2005).

7. Nogales, E., Wolf, S. G. \& Downing, K. H. Structure of the alpha beta tubulin dimer by electron crystallography. Nature 391, 199-203 (1998).

8. Nogales, E., Whittaker, M., Milligan, R. A. \& Downing, K. H. High-resolution model of the microtubule. Cell 96, 79-88 (1999).

9. Giannakakou, P. et al. A common pharmacophore for epothilone and taxanes: molecular basis for drug resistance conferred by tubulin mutations in human cancer cells. Proc. Natl. Acad. Sci. U S A 97, 2904-9 (2000). 
10. Diaz, J. F., Barasoain, I. \& Andreu, J. M. Fast kinetics of taxol binding to microtubules. Effects of solution variables and microtubule-associated proteins. J. Biol. Chem. 278, 8407-19 (2003).

11. Diaz, J. F., Barasoain, I., Souto, A. A., Amat-Guerri, F. \& Andreu, J. M. Macromolecular accessibility of fluorescent taxoids bound at a paclitaxel binding site in the microtubule surface. J. Biol. Chem. 280, 3928-37 (2005).

12. Diaz, J. F., Menendez, M. \& Andreu, J. M. Thermodynamics of ligand-induced assembly of tubulin. Biochemistry 32, 10067-77 (1993).

13. Sato, B. et al. A new antimitotic substance, FR182877. I. Taxonomy, fermentation, isolation, physico-chemical properties and biological activities. J. Antibiot. (Tokyo) 53, 123-30 (2000).

14. Buey, R. M. et al. Interaction of epothilone analogs with the paclitaxel binding site; relationship between binding affinity, microtubule stabilization, and cytotoxicity. Chem. Biol. 11, 225-36 (2004).

15. Diaz, J. F., Strobe, R., Engelborghs, Y., Souto, A. A. \& Andreu, J. M. Molecular recognition of taxol by microtubules. Kinetics and thermodynamics of binding of fluorescent taxol derivatives to an exposed site. J. Biol. Chem. 275, 26265-76 (2000).

16. Barshop, B. A., Wrenn, R. F. \& Frieden, C. Analysis of numerical methods for computer simulation of kinetic processes: development of KINSIM--a flexible, portable system. Anal. Biochem. 130, 134-45 (1983).

17. Derry, W. B., Wilson, L. \& Jordan, M. A. Substoichiometric binding of taxol suppresses microtubule dynamics. Biochemistry 34, 2203-11 (1995). 
18. Giannakakou, P. et al. Paclitaxel-resistant human ovarian cancer cells have mutant beta-tubulins that exhibit impaired paclitaxel-driven polymerization. J. Biol. Chem. 272, 17118-25 (1997).

19. Adam, G. C., Vanderwal, C. D., Sorensen, E. J. \& Cravatt, B. F. (-)-FR182877 is a potent and selective inhibitor of carboxylesterase-1. Angew. Chem. Int. Ed. Engl. 42, 5480-4 (2003).

20. Vanderwal, C. D., Vosburg, D. A., Weiler, S. \& Sorensen, E. J. An enantioselective synthesis of FR182877 provides a chemical rationalization of its structure and affords multigram quantities of its direct precursor. J. Am. Chem. Soc. 125, 5393-407 (2003).

21. Yoshimura, S., Sato, B., Kinoshita, T., Takase, S. \& Terano, H. A new antimitotic substance, FR182877. III. Structure determination. J. Antibiot. (Tokyo) 53, 615-22 (2000).

22. Hadvary, P., Sidler, W., Meister, W., Vetter, W. \& Wolfer, H. The lipase inhibitor tetrahydrolipstatin binds covalently to the putative active site serine of pancreatic lipase. J. Biol. Chem. 266, 2021-7 (1991).

23. Liu, S., Widom, J., Kemp, C. W., Crews, C. M. \& Clardy, J. Structure of human methionine aminopeptidase-2 complexed with fumagillin. Science 282, 1324-7 (1998).

24. Evans, D. C., Watt, A. P., Nicoll-Griffith, D. A. \& Baillie, T. A. Drug-protein adducts: an industry perspective on minimizing the potential for drug bioactivation in drug discovery and development. Chem. Res. Toxicol. 17, 316 (2004).

25. Henness, S. \& Perry, C. M. Orlistat: a review of its use in the management of obesity. Drugs 66, 1625-56 (2006). 
26. Brabec, V. \& Kasparkova, J. Modifications of DNA by platinum complexes. Relation to resistance of tumors to platinum antitumor drugs. Drug. Resist. Updat. 8, 131-46 (2005).

27. Parness, J. \& Horwitz, S. B. Taxol binds to polymerized tubulin in vitro. J. Cell. Biol. 91, 479-87 (1981).

28. Diaz, J. F., Andreu, J. M., Diakun, G., Towns-Andrews, E. \& Bordas, J. Structural intermediates in the assembly of taxoid-induced microtubules and GDP-tubulin double rings: time-resolved X-ray scattering. Biophys. J. 70, 2408-20 (1996).

29. Weisenberg, R. C., Borisy, G. G. \& Taylor, E. W. The colchicine-binding protein of mammalian brain and its relation to microtubules. Biochemistry $\mathbf{7}$, 4466-79 (1968).

30. Andreu, J. M. \& Barasoain, I. The interaction of baccatin III with the taxol binding site of microtubules determined by a homogeneous assay with fluorescent taxoid. Biochemistry 40, 11975-84 (2001).

31. Krauhs, E. et al. Complete amino acid sequence of beta-tubulin from porcine brain. Proc. Natl. Acad. Sci. U S A 78, 4156-60 (1981). 


\section{FIGURE LEGENDS}

Figure 1. Biochemistry of the cyclostreptin-microtubule interaction. (a) Chemical structure of cyclostreptin and analogues. (b) HPLC-MS analysis of cyclostreptin extracted from pellets (black) and supernatants (red) after incubation with (solid lines) and without (dashed lines) stabilized microtubules. (c) Binding of Flutax-2 to stabilized microtubules preincubated with cyclostreptin or DMSO. (d) Kinetics of displacement of Flutax-2 from microtubules by cyclostreptin at 2 (black), 5 (yellow), 10 (magenta), 20 (green) or $40 \mu \mathrm{M}$ (blue) or $2 \%$ DMSO (orange). Left Inset: Displacement of Flutax-2 by docetaxel at 2 (black solid line) or $20 \mu \mathrm{M}$ (red dotted line). Right Inset: Dependence of the observed rate constant on [cyclostreptin], solid line fit of the data to the kinetic model proposed.

Figure 2. Inhibition of binding of Flutax-2 to PtK2 cytoskeletons by preincubation with cyclostreptin (a-c) and irreversibility of microtubule effects on PtK2 cells grown in cyclostreptin (d-i). (a-c) Cytoskeletons were preincubated with DMSO and stained with Flutax-2 (a), $10 \mu \mathrm{M}$ cyclostreptin (b) or $10 \mu \mathrm{M}$ paclitaxel (c). Insets: Mitotic spindles stained with Flutax-2. (d-f) Cells cultured for $7 \mathrm{~h}$ in the presence of DMSO and immunostained (d), $5 \mu \mathrm{M}$ cyclostreptin (e) or $10 \mu \mathrm{M}$ paclitaxel (f). (g-i), Cells washed after $7 \mathrm{~h}$ and left in culture for $16 \mathrm{~h}$. DMSO treatment $(\mathbf{g})$, cyclostreptin treatment $(\mathbf{h})$ and paclitaxel treatment (i). The size bar represents $10 \mu \mathrm{m}$, and all panels and insets have the same magnification.

Figure 3. MS analyses of cyclostreptin binding to tubulin. Total ion chromatogram of the precursor ion scanning of fragment at $m / z 249.0$ from control (a) or cyclostreptin-treated (b) tubulin samples, digested with trypsin (Try) or chymotrypsin (Chy). (c) MRM experiments with unassembled, cyclostreptin-treated dimeric tubulin samples. The upper insets show MRM results for the corresponding 
dimeric tubulin control samples. Black arrows indicate the retention time expected for signals from Peaks 2 (left, trypsin) and 5 (right, chymotrypsin). (d) Sequence of the $\beta$ tubulin peptide (residues 219-243) containing the peptides labeled. Black triangles indicate the theoretical chymotrypsin cleavage sites within the tryptic peptide. (e) MRM experiments with trypsin-digested tubulin extracted from untreated or cyclostreptin-treated cells.

Scheme 1. Possible reaction mechanisms between cyclostreptin and nucleophiles. (a) acylation reaction of the lactone through nucleophilic attack at $\mathrm{C} 1$. (b) Top, simple addition of the nucleophile to $\mathrm{C} 17$; bottom, addition-elimination of the nucleophile at the $\mathrm{C} 2-\mathrm{C} 17$ bond, with formation of a 9-member ring alcohol. 
TABLE 1

Dependence on order of ligand addition for the binding of discodermolide, paclitaxel, or epothilone $B$ to the taxoid site.

\begin{tabular}{|l|l|l|l|l|l|l|}
\hline \multicolumn{7}{|c|}{ Binding $^{\mathrm{a}}$ of $2 \mu \mathrm{M}$} \\
\hline & \multicolumn{7}{|c|}{$\left[{ }^{3} \mathrm{H}\right]$ Discodermolide } & {$\left[{ }^{14} \mathrm{C}\right]$ Epothilone B } & \multicolumn{2}{l|}{$\left[{ }^{3} \mathrm{H}\right]$ Paclitaxel } \\
\hline & A & B & A & B & A & B \\
\hline$(20 \mu \mathrm{M})$ & $-------\%$ radioactive compound bound ${ }^{\mathrm{b}} \pm$ SD & ---------- & \\
\hline Cyclostreptin & $96 \pm 4$ & $19 \pm 6$ & $79 \pm 10$ & $12 \pm 1$ & $60 \pm 2$ & $25 \pm 2$ \\
\hline Epothilone A & $95 \pm 1$ & $96 \pm 5$ & $49 \pm 1$ & $49 \pm 1$ & $46 \pm 3$ & $49 \pm 1$ \\
\hline Epothilone B & $76 \pm 1$ & $79 \pm 5$ & $9 \pm 2$ & $9 \pm 1$ & $31 \pm 1$ & $33 \pm 4$ \\
\hline Discodermolide & $27 \pm 1$ & $31 \pm 10$ & ND $^{\mathrm{C}}$ & ND & ND & ND \\
\hline
\end{tabular}

${ }^{a} A$ columns: the radiolabeled ligand was added prior to the nonradiolabeled competitor. $B$ columns: the nonradiolabeled competitor was added prior to the radiolabeled ligand. ${ }^{\mathrm{b}}$ The figures represent the percentage of radiolabeled compound bound in the presence of the competitor as compared with the compound bound in its absence. 'ND not determined. 
TABLE 2

Effects of cyclostreptin as compared with paclitaxel and docetaxel on the growth of human carcinoma cells.

\begin{tabular}{|c|c|c|c|c|c|c|}
\hline \multirow{2}{*}{\multicolumn{7}{|c|}{$I_{50}(\mathrm{nM}) \pm S D^{a}$}} \\
\hline Cell line & & & & & & \\
\hline Compound & A2780 & A2780/AD & $1 \mathrm{~A} 9$ & PTX10 & PTX22 & A549 \\
\hline Paclitaxel & $1 \pm 0.3$ & $900 \pm 200(900)^{b}$ & $1.1 \pm 0.2$ & $30 \pm 9(27)$ & $19 \pm 5(17)$ & $3.6 \pm 0.4$ \\
\hline Docetaxel & $0.5 \pm 0.1$ & $285 \pm 60(570)$ & $0.6 \pm 0.1$ & $N D^{c}$ & ND & $7.2 \pm 0.3$ \\
\hline Cyclostreptin & $43.5 \pm 4$ & $51 \pm 12(1.2)$ & $44 \pm 6$ & $240 \pm 50(5)$ & $58 \pm 7(1.3)$ & $45.5 \pm 11$ \\
\hline $\begin{array}{l}\text { Epoxidized } \\
\text { cyclostreptin }\end{array}$ & Inactive $^{\mathrm{d}}$ & Inactive & Inactive & Inactive & Inactive & Inactive \\
\hline $\begin{array}{l}\text { Reduced } \\
\text { Cyclostrepytin }\end{array}$ & Inactive & Inactive & Inactive & Inactive & Inactive & Inactive \\
\hline
\end{tabular}

${ }^{a} C_{50}$ values determined in the ovarian carcinoma lines A2780 (parental line), A2780/AD (a MDR line overexpressing P-gp), 1A9 (a clone of A2780), and PTX10 and PTX22 (paclitaxel-resistant tubulin mutants derived from 1A9) and the non-small lung cell carcinoma line A549. $\mathrm{IC}_{50}$ values were obtained in at least four independent experiments. ${ }^{\mathrm{b}}$ The numbers in parentheses are the calculated relative resistance values, obtained by dividing the $\mathrm{IC}_{50}$ value of the resistant line by the $\mathrm{IC}_{50}$ value of the parental line. ${ }^{\mathrm{C}} \mathrm{ND}$ not determined. ${ }^{\mathrm{d}}$ Inactive, no inhibition at $5 \mu \mathrm{M}$. 
a

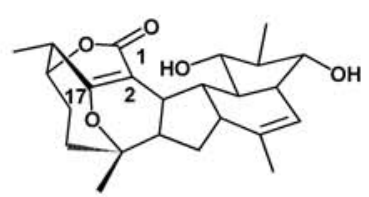

Cyclostreptin

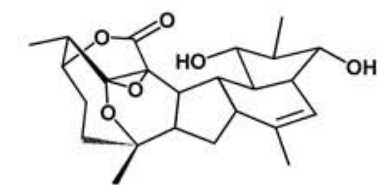

Epoxidated cyclostreptin

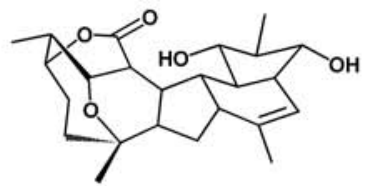

C Reduced cyclostreptin

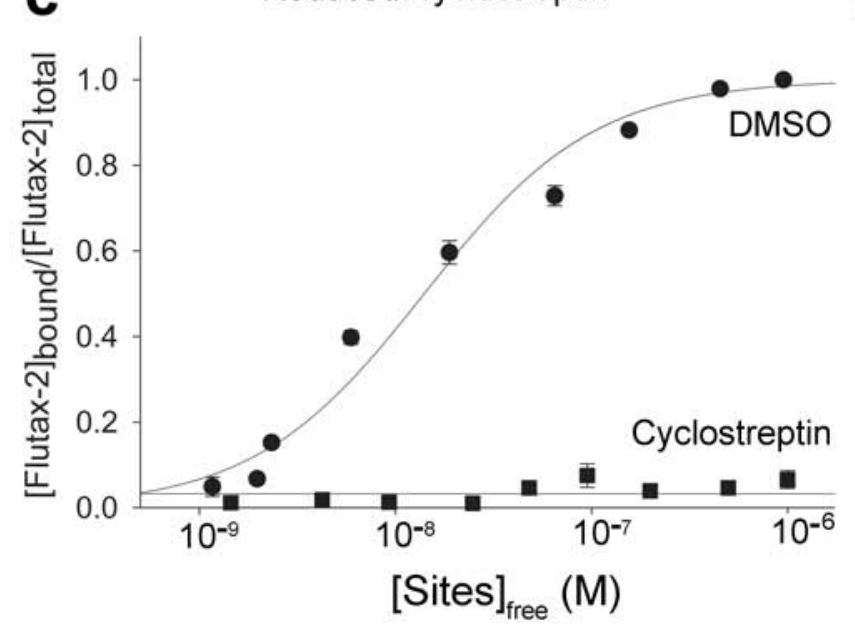

b

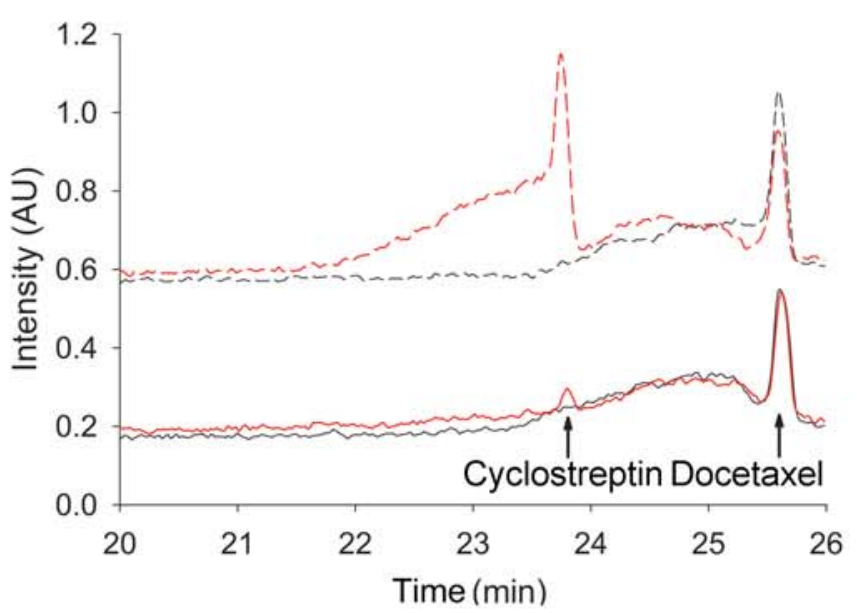

d

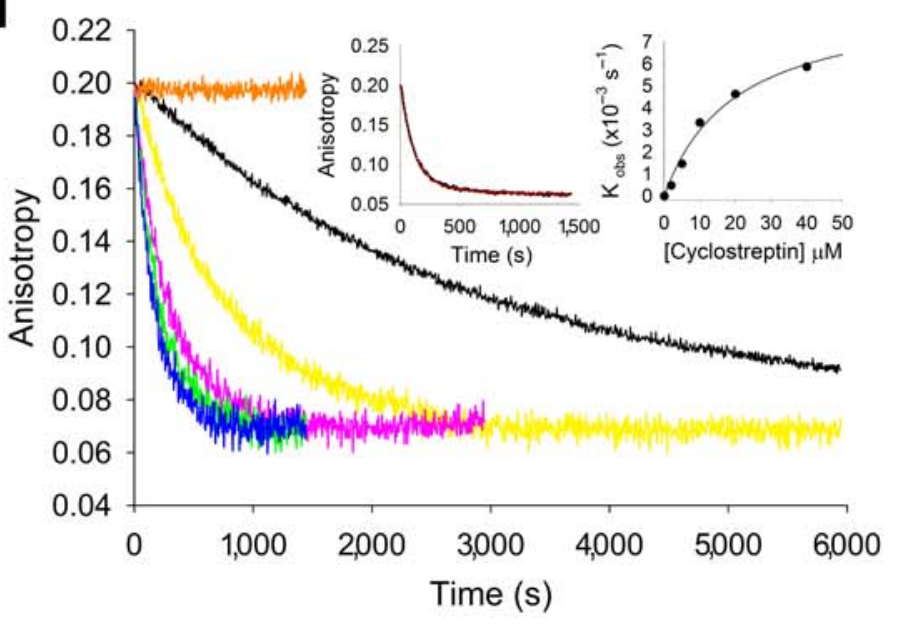



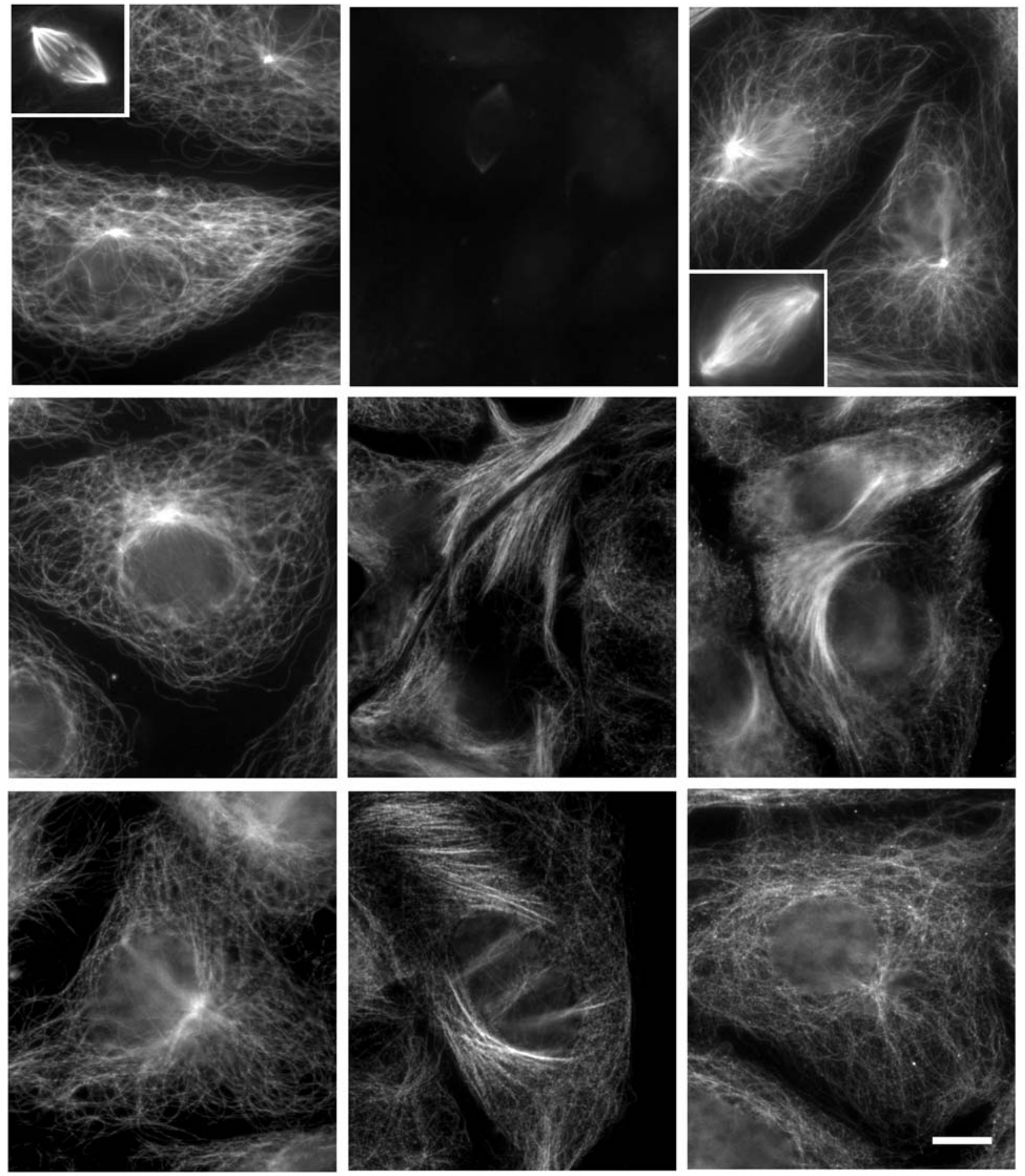

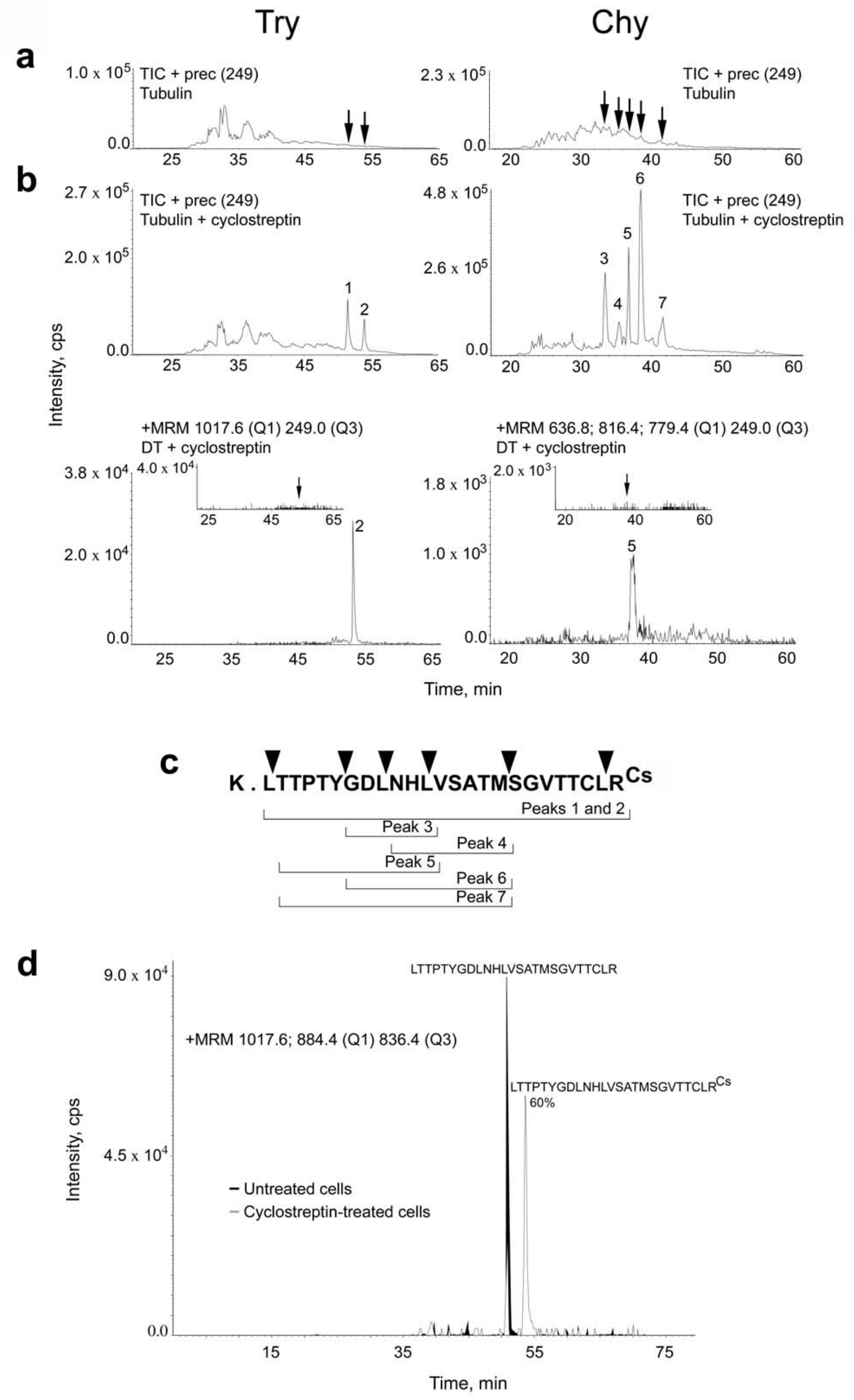
a

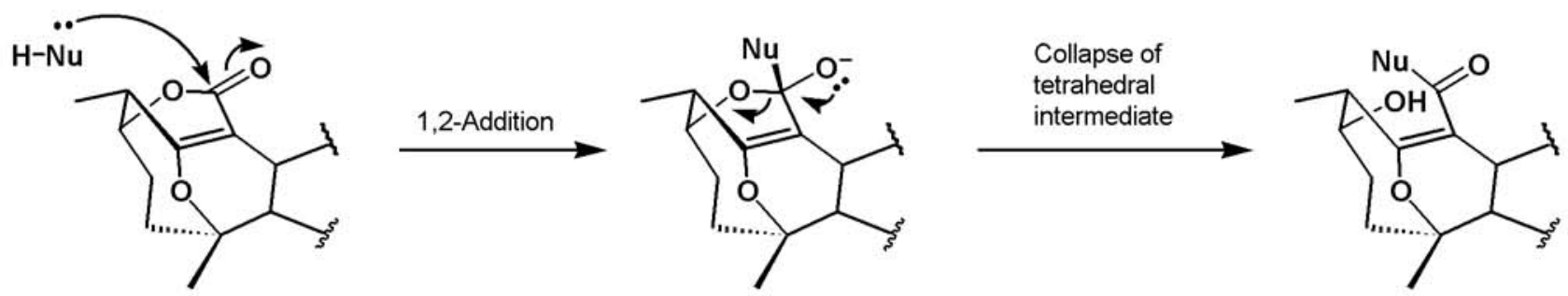

b

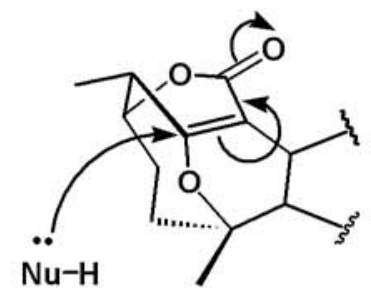

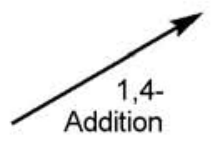

(2)
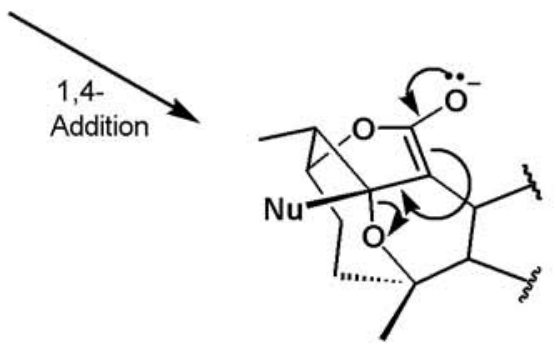

Enolate protonation

tetrahedral

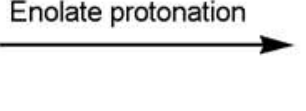

$\stackrel{\text { B-Elimination }}{\longrightarrow}$

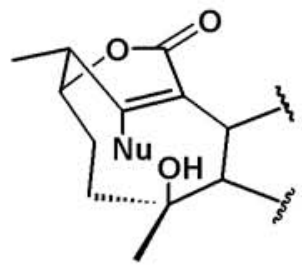

